\title{
Kahramanmaraş Domuz (Boğaz) Deresi Kuşaklama Kanalının HEC-RAS Modeli
}

\author{
Burcu Ercan ${ }^{1, * *}$, Ayşe Ece Yağcı ${ }^{2, * *}$, Mehmet Ünsal| $^{2, *}$ \\ ${ }^{1}$ Kilis 7 Aralık Üniversitesi, Mühendislik-Mimarlık Fakültesi, Inşaat Mühendisliği Bölümü, Kilis. \\ ${ }^{2}$ Kahramanmaraş Sütçü İmam Üniversitesi, Mühendislik ve Mimarlık Fakültesi, İnşaat Mühendisliği Bölümü, Kahramanmaraş. \\ *ORCID: 0000-0001-5864-7040, , ORCID: 0000-0002-3185-1831, "** ORCID: 0000-0001-6973-9995
}

\section{Özet}

Canlıların yașam kaynağı olan su kontrol altına alınmadı̆̆ı durumlarda ciddi mal ya da can kayıplarına neden olmaktadır. Ayrıca küresel ısınmanın etkilerini hissettiğimiz bugünlerde suyun planlı kullanımı büyük önem taşımaktadır. Afetlerden biri olan taşkın oluşumu insan ya da doğa kaynakl olabilir. Bir akarsu taşkın olușturduğunda tarım arazilerine, altyapı tesislerine, insanların sosyal ve ekonomik hayatlarına, çevrede bulunan yerleşim yerlerine ciddi zararlar vermektedir. Bir ülkenin sosyo-ekonomik durumunun gelişiminde su kaynaklarl yönetimi önemli bir role sahiptir. Sel riskini önlemek ve ayrlca suyun kaynaktan ihtiyaç noktalarına taşınmasını sağlamak için kanallar kullanılır. Trapez, dikdörtgen, yarım daire ve üçgen şekillerde modellenen açık kanalların tasarımını HEC-RAS programında yapmak mümkündür. Bu çalışmada Kahramanmaraş ilinin Oniki şubat ilçe merkezindeki 6-7 mahallede taşkınların oluşması sonucunda maddi ve manevi kaybı önlemek amacıyla yapılan kușaklama kanalı projesinin hesapları, HEC-RAS programı ile modellenip sonuçlar karşılaştırılmıştır. Mockus ve rasyonel metot kullanılarak bulunan sonuçlar ile HEC-RAS sonuçları arasındaki uyum incelenmistir. Domuz (Boğaz) deresi kuşaklama kanalının; kanal boyunca meydana gelecek su derinlikleri ve hızları HEC-RAS yardımıyla hesaplanmıştır. Çalışma sonucunda proje ve model sonuçlarının birbiriyle çok uyumlu olduğu görülmüştür.

\section{Anahtar Sözcükler}

HEC-RAS, Domuz Deresi, Kanal Tasarım, Düzenli Akım

\section{HEC-RAS Model of Kahramanmaras Domuz (Bogaz) Stream Interception Channel}

\begin{abstract}
Water, which is the source of life for living things, causes serious loss of property or life when it is not controlled. Additionally, the planned usage of water is of great importance nowadays when we feel the effects of global warming. One of the disasters, flood formation may be human or nature-originated. When a river forms flood, it causes severe damage to agricultural land, infrastructure facilities, people's social and economic life, settlements in the environment. Water resources management plays an important role in the development of a country's socio-economic situation. Channels are used to prevent flood risk and also to ensure that the water moves from source to need. It is possible to design open channels which are modeled in trapezoid, rectangular, semi-circle and triangular shapes in HEC-RAS program. In this study, the calculations of the flood channel project were modeled by HEC-RAS program and the results were compared between project results. Aim of this project is to protect from the harm financial and emotional damage caused by flood in 6-7 streets of Kahramanmaraş province's Oniki şubat district center. The agreement between the results using Mockus and the rational method and the HEC-RAS results was examined. Domuz (Boğaz) stream interception channel; the water depths and speeds that will form along the channel were calculated with the help of HEC-RAS. As a result of the study, it was observed that the results of the Project and model are very compatible with each other.
\end{abstract}

$\underline{\text { Keywords }}$

HEC-RAS, Domuz Stream, Channel Design, Steady Flow

\section{Giriş}

Taşkınların doğal bir afet olduğu bilinse de, insanların doğaya sürekli müdahaleleri sonucunda gün geçtikçe sayıları ve şiddetleri artmaktadır. Ülkemizde, bölgesel iklim koşulları, topografya ve yağış alanı büyüklüğü etkenlerinin birleşimi büyük taşkınlara neden olur. Doğal afetlerin önüne geçebilmek mümkün olmasa da yıkıcı etkilerinin kontrol atına alınabilmesi ve önlenebilmesi için koruma önlemleri alınabilmektedir. Taşkınların meydana getirdikleri zararlar dünyada olduğu gibi ülkemizde de büyük önem taşıdığından, doğabilecek ekonomik ve sosyal zararları en aza indirmek büyük önem taşımaktadır. Bölge taşkın planları, hidrometrik - meteorolojik gözlem çalışmaları ve taşkın envanterleri gibi çalışmalar taşkınları en aza indirmeye yardımcı olabilecek unsurlardır. Alınacak önlemlerin başında dere yatağı ıslah çalışmaları ve akarsu üzerinde sanat yapılarının düzenlenmesi gelir.

* Sorumlu Yazar: Tel: + 90 (344) 3001666 Faks: +90 (344) 3001602

E-posta: burc6666@gmail.com (Ercan B), ayseeceyagci@gmail.com (Yağcı A.E) munsal@ksu.edu.tr (Ünsal M)
Gönderim Tarihi / Received : 22/05/2018

Kabul Tarihi / Accepted : : 09/08/2018 
$\mathrm{Bu}$ çalışmaların yapılabilmesi için akarsuyun debisi ve buna bağlı su yüksekliği bilinmelidir. Bu hesap ve analizlerin yapılabilmesi için kolaylık sağlayan paket programlar geliştirilmiştir. Bu çalışmada, bu paket programlardan biri olan HEC-RAS (HydrologicEngineeringCenter's - River Analysis System) kullanılmıştır.

Üyüklüoğlu vd. (2015), çalışmalarında Antalya - Manavgat’ta bulunan Ilıca Deresinde HEC-RAS programıyla su yüzü profillerini modellemiştir. Su üst kotlarını tespit ederek taşkın yayılım alanları elde etmişlerdir. Bu sonuçlardan yararlanılarak taşkını dere yatağında tutacak bir güzergah belirlenmiş ve ıslah çalışması yapılarak tekrar HEC-RAS programı kullanılarak taşkının kontrol altına alındı ğını belirlemişlerdir.

Mehta vd. (2014), Surat şehrinde meydana gelen sellerin Tapi nehrinde üzerinde bulunan Ukai barajının ani su tahliyelerinden kaynaklandığını ifade etmişlerdir. Tapi nehrinde gerçekleşen sellerin Surat şehri ve çevresini ciddi anlamda etkilediğini, anılan bölgede 29 yılda 14 büyük sel olayı meydana geldiğini ve bu sel olaylarına karşı önlem almak çeşitli çalışmalarda bulunmuşlardır. Bu amaçla HEC-RAS yazılımıyla geçmiş yıllardaki sel verileri kullanılarak, nehrin eğimi ve akım değerlerinin göz önünde bulundurulmasıyla, taşıma kapasitesi ve kararlılığı değerlendirilmiştir. 2006 yılında ki sel olayı incelendiğinde bölgenin batı ve güneybatı bölgelerinin doğu bölgesine göre daha çok zarar gördüğü sonucuna varılmış ve Surat şehrinin \%95'nin sular altında kaldığı görülmüş ve taşkından korunmak amacıyla istinat duvarlarının ve bentlerin yükseltilmesi gerektiği sonucuna varmışlardır. Özdemir (2007), Havran Çayı üzerinde ArcGIS, HecGeoras ve HEC-RAS yazılımlarıyla 2 farklı senaryo baz alarak taşkın haritaları oluşturmuştur.

Efe ve Önen (2015), çalışmalarında Batman Çayı'nın Yeni Malabadi Köprüsü ile Diyarbakır - Batman Karayolu Köprüsü arasında kalan kesimine ait taşkın analizini gerçekleştirmişler. Düşük eğime, fakat yüksek debiye sahip Batman Çayı üzerinde 165 en kesit alınmış, 5 - 10 - 25 - 50 - 100 ve 500 yıllık tekerrür aralığı taşkın debilerine göre su seviyesi yüksekliklerini hesaplamışlar. Q50 ve üzerindeki birçok en kesitin yetersiz kaldığını, geniş tabanlı vadi boyunca düşük bir eğim olmasına rağmen Q500'de su yüzü yüksekliği 4m’ye ulaştığı gözlemlemişlerdir.

Horritt ve Bates (2002), İngiltere'nin Severn nehri üzerinde $60 \mathrm{~km}$ uzunluğunda bir parçasının 1D ve 2D modellerini incelenmiştir. HEC-RAS, LISFLOOD-FP ve TELEMAC-2D yazılımları kullanılarak, kanal sürtünmesi ve taşkın yatağı serbest değişken kabul edilip, taşkın alanı ve mansap akımı 3 model için ölçülendirilmiştir. Çalışmaya göre, HEC-RAS ve TELEMAC-2D'nin akım ya da taşkın alanının verilerine göre ayarlanabileceğini ve iyi sonuçlar verebileceği, fakat LISFLOOD-FP yazılımının kabul edilebilir sonuçlar için, bağımsız taşkın alanı verilerine karşı ayarlanması gerektiği sonucuna varmışlardır. Modellerin farklı performansları, sürtünme parametresinde ki değişimlere olan farklı tepkilerinden kaynaklandığını belirleyip, yapılan modellemeler ve çalışma sonunda en iyi sonuçlar veren yazılımın HEC-RAS olduğunu ifade etmişlerdir.

HEC-RAS, doğal akarsu ve diğer kanallardan su akışının hidroliğini modelleyen bir bilgisayar programıdır. Bu program, kendi yetki alanlarındaki nehirleri, limanları ve diğer kamu işlerini yönetmek için ABD Savunma Bakanlığı, Mühendisler Kolordusu tarafından geliştirilmiştir ve 1995 yılında halka açılmasından bu yana birçok kişi tarafından geniş çapta kabul görmüştür. Amerika'nın Kaliforniya eyaletinde yer alan Davis şehrinde, Hidroloji Mühendisliği Merkezi (Hydrologic Engineering Center-HEC), kanal mühendisliği analizinde ve taşkın yatağının belirlenmesinde hidrolik mühendislerine yardımcı olmak için Nehir Analiz Sistemini (River Analysis System-RAS) geliştirilmiştir. Versiyon 5.0'dan önceki sürümlerde program tek boyutluydu, yani kesit şekil değişikliğinin, kıvrımların hidrolik etkilerinin ayrıca diğer 2 ve 3 boyutlu akım yönlerinin doğrudan modellemesi yoktu. Versiyon 5.0 sürümünün güncellenmesiyle, sediment taşınımı modelleme özelliğinin yanı sıra iki boyutlu akış modellemesi özelliği eklendi. Kararlı akış için HEC-RAS'ın temel hesaplama prosedürü, tek boyutlu enerji denkleminin çözümüne dayanmaktadır. Enerji kayıpları sürtünme ve kanalda ya da yatakta gerçekleşen daralma / genişleme ile değerlendirilir. Momentum denklemi ise, su yüzey profilinin hızla değiştiği durumlarda kullanılabilir. Bu durumlar arasında hidrolik sıçramalar, köprü hidroliği ve nehir kenarlarındaki profillerin değerlendirilmesi yer almaktadır. HEC-RAS, bir kanal ağı, bir dal sistemi veya tek bir nehir uzantısını modellemek için donatılmıştır. Köprülerin, menfezlerin, savakların ve yapıların etkileriyle birlikte, kritik, süperkritik ve karma akış rejimi akışını modelleme yeteneğine sahiptir.

Hec-GeoRas, AutoCAD çizimlerini kullanabilir, GIS verilerini HEC-RAS'a aktarmada yardımcı bir arayüz görevi görür, kesitleri kesebilir ve taşkın haritaları üretebilir. Birden fazla HEC-RAS modelini aynı anda düzenleyebilir, mühendisin modeller arasında kopyala- yapıştır yapabilmesine olanak sağlar. Hec-GeoRas yardımıyla çalışma alanının topografik özellikleri kolaylıkla HEC-RAS ‘a aktarılır ve diğer veri girişleri HEC-RAS ‘ta yapılabilir. İlk önce hidrolojik, daha sonra hidrolik analiz yapılır. Bu program inşaat mühendisliği alanında taşkın analizi ve kanal tasarımı için yaygın olarak kullanılır. Kanal tasarımında manning katsayısı, projenin istenen tekerrür aralığına göre suyun debisi, kanal eğimi ve akımın türü gibi veriler programa girdi olarak kaydedilir (Ünsal ve Nalcıŏlu 2016).

\section{2. Çalışma Alanı ve Yöntem}

Kahramanmaraş ilinin, Oniki Şubat ilçe merkezinde yer alan, 800 m rakıma sahip olan Domuz deresi kuzeyden güneye doğru akmaktadır ve birçok meskende taşkından kaynaklanan hasarlara neden olmuştur. Çalışma alanının lokasyonu Şekil 1 'de görüldüğü gibidir. 


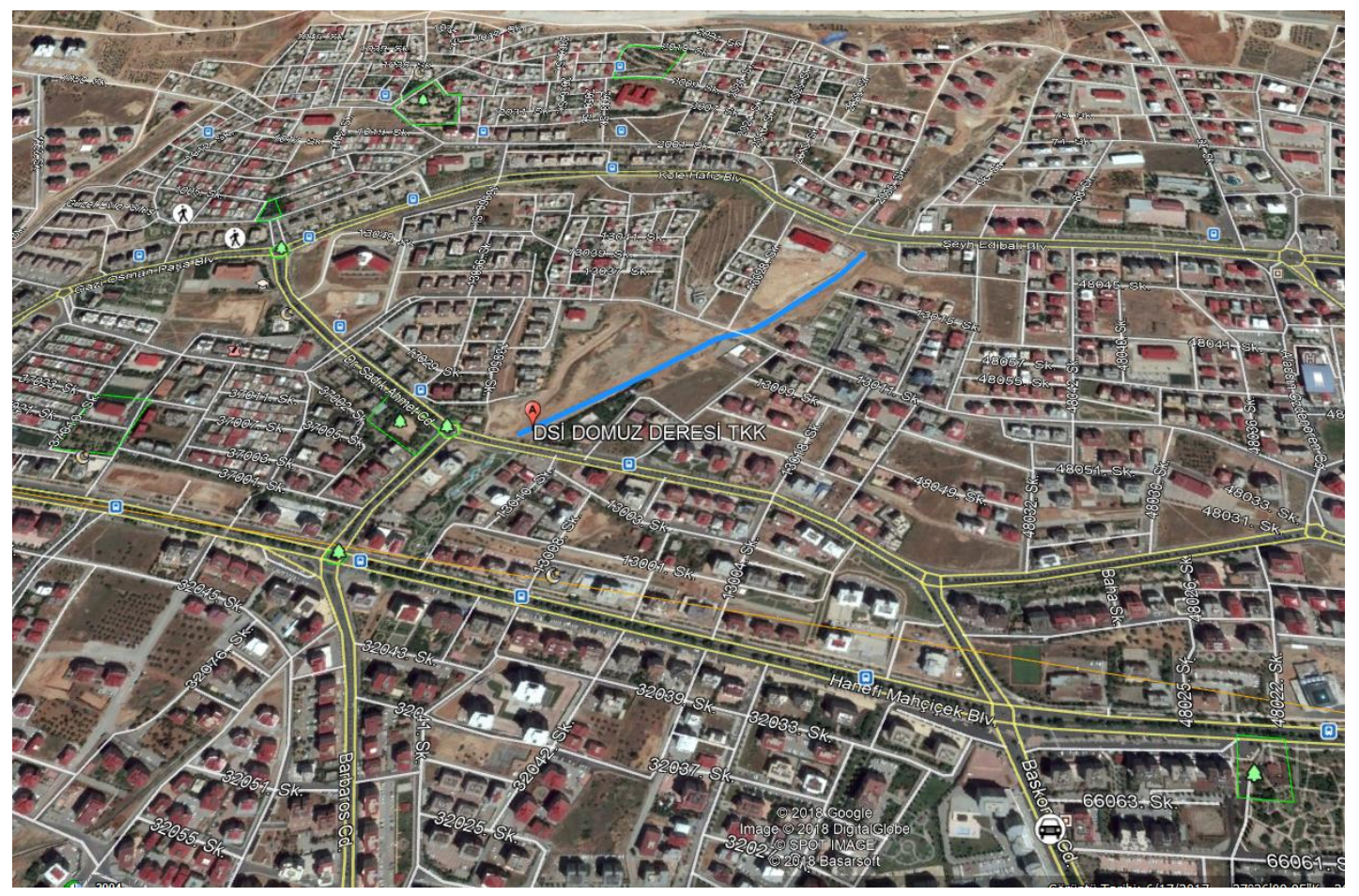

Şekil 1: Domuz deresi'nin harita üzerinde konumu

Cancığın, 4 kurudere ve Domuz deresi'nin ilkbahar ve sonbahar aylarında yağan yağmurlar ve eriyen karlar nedeniyle taşkın oluşturduğu görülmüştür. Bu durum sonucunda bu bölgede gerçekleşecek taşkınların maddi ve manevi kayıplara neden olabileceği göz önüne alınarak, 2017 yılında 6-7 mahallenin içinden geçen Domuz (Boğaz) deresinin risk oluşturması nedeniyle kuşaklama kanalı projesi yapılmıştır. Islah çalışması sonucunda Cancığın ve 4 kurudere kuşaklama kanalı yardımıyla, Domuz deresi’ne mansaplanmıştır. Bölgenin kuzey - güney yönünde eğimi \% 9-14 aralığındadır. Domuz deresi yağış havzası $3,56 \mathrm{~km}^{2}$ büyüklüğe sahiptir. Projenin amacı bölgenin korunması ve ıslah çalışması olduğu için 100 yıllık tekrar aralığı değeri ve bunun yanında hava payı olarak 500 yıllık tekrar aralığı debi değerleri kullanılmıştır. Sır, Menzelet ve Kartalkaya barajlarının su toplaması ile birlikte, kuzeyinde sert olmayan karasal iklim, güneyinde ise Akdeniz iklimi hakim olan Kahramanmaraş ili bölgesinin ikliminde değişikliklere neden olmuştur.

Projede belirtilen yağış havzasının, Mockus ve Rasyonel $\left(\mathrm{Q}_{\mathrm{p}}=\right.$ CIA/3.6) yöntemler yardımıyla pik debi değerleri hesaplanmış ve bu değerler üzerinden hesaplamalar yapılmıştır. Taşkınlar 2 farklı yöntem grubu yardımıyla hesaplanır: istatistiki yöntemler ve deterministik yöntemler. Deterministik yöntemler, istatistik yöntemlere de yer veren sentetik birim hidrograf yöntemleri ile amprik formüller, havza alan büyüklüğü, suların toplanma zamanı, birim hidrografın pike ulaşma zamanı ve Lag-time parametrelerine göre hesaplanır. Deterministik birim hidrograf yöntemi olan Mockus yönteminin birim hidrograf kriteri toplanma zamanı 30 saat veya daha az olan istasyonlar ve genellikle üzerinde akım gözlem istasyonu bulunmayan derelerde kullanılır. Mockus yönteminin hesaplama şekli Denklem 1'de verilmiştir.

$$
\begin{aligned}
& Q_{p}=K \times A \times \frac{h_{a}}{T_{p}} \\
& T_{c}=0.00032 \times \frac{L^{0.77}}{S^{0.385}} \\
& D=2 \times \sqrt{T_{c}} \\
& T_{p}=0.5 \times \Delta D \times 0.6 \times T_{c} \\
& T_{r}=1.67 \times T_{p} \\
& T_{b}=T_{p}+T_{r}
\end{aligned}
$$


Denklemde geçen $\mathrm{Q}_{\mathrm{p}}$ : pik debi, K: 0.208, $\mathrm{h}_{\mathrm{a}}$ : doğrudan akış yüksekliği, $\mathrm{T}_{\mathrm{p}}$ : hidrografın yükselme zamanı, $\mathrm{T}_{\mathrm{r}}$ : alçalma zamanı, $\mathrm{T}_{\mathrm{b}}$ : hidrografin taban süresi, $\mathrm{D}$ : taşkını meydana getiren yağış süresi, $\Delta \mathrm{D}$ : birim sağanak süresi $\leq \mathrm{T}_{\mathrm{c}} / 5$ (taşkınlarda birim sağanak süresinin seçilmesi önemli rol oynamaktadır. Genel olarak ilk 6 saatlik sağanak süresi için $\Delta \mathrm{D}=1, \mathrm{~T}_{\mathrm{c}}<3$ olan durumlarda ise $\Delta \mathrm{D}=0.5$ alınır).

Ampirik formül olan Rasyonel yöntem ise yeteri kadar ölçümü bulunmayan yan derelerin ve yüzeysel drenaj kanallarının kapasite hesaplarında kullanılmaktadır $5 \mathrm{~km}^{2}$ 'den küçük havzalar için doğru sonuçlar vermektedir fakat DSİ $1 \mathrm{~km}^{2}$ 'den büyük havzalarda bu yöntemi kullanmıyor. Bu çalışmada 1975-2006 yılları arasında ki aylık yağış verileri kullanılarak proje hesapları yapılmıştır. Projede mevcut kuşaklama kanalının dikdörtgen kesite sahip, $621 \mathrm{~m}$ uzunluğunda 2 parçadan oluşan $(0+00-0+147 \mathrm{~km}$ ve $0+147-0+621 \mathrm{~km})$ bölümünde HEC-RAS 5.0.3 yazılımı kullanılarak modelleme çalışması yapılmıştır. $621 \mathrm{~m}$ uzunluğundaki kanalda 2 ayrı eğim bulunmaktadır. Bu projede 100 ve 500 yıllık tekerrür aralığına göre debi değerleri kullanılmıştır. Bu çalışmada kullanılan değerler aşağıdaki tabloda verilmiştir (Tablo 1).

Tablo 1: Proje verileri

\begin{tabular}{|c|c|c|c|c|c|}
\hline KM & & Debi $\left(\mathbf{m}^{\mathbf{3}} / \mathbf{s}\right)$ & Manning katsayısı & Eğim & Kanal tipi \\
\hline \multirow{2}{*}{$0+00 \mathrm{~km}-0+147 \mathrm{~km}$} & $\mathrm{Q}_{500}$ & 42,88 & 0,024 & 0,0815 & Dikdörtgen \\
\cline { 2 - 4 } & $\mathrm{Q}_{100}$ & 36,45 & & & \\
\hline \multirow{2}{*}{$0+147 \mathrm{~km}-0+621 \mathrm{~km}$} & $\mathrm{Q}_{500}$ & 53,32 & 0,024 & 0,126 & Dikdörtgen \\
\cline { 2 - 4 } & $\mathrm{Q}_{100}$ & 45,32 & & \\
\hline
\end{tabular}

HEC-RAS programında modelleme yapabilmek için projede yer alan 2 farklı kanal eğimi $\left(\mathrm{j}_{1}=0.0815\right.$ ve $\left.\mathrm{j}_{2}=0.126\right)$, kanalın Manning katsayı değeri ve kanal kesitleri tanımlanmıştır. Akım rejimi karışık akım olarak belirlenmiştir. Modellemede ilk olarak kanal kesitleri ve uzunluğu girildikten sonra diğer bilgiler işlenmiştir ve 13 adet kesit alınmıştır. $\mathrm{Q}_{500}$ ve $\mathrm{Q}_{100}$ için tablodaki veriler kullanılarak yapılan modellemenin kesit görüntüsü Şekil 2'de verilmektedir.
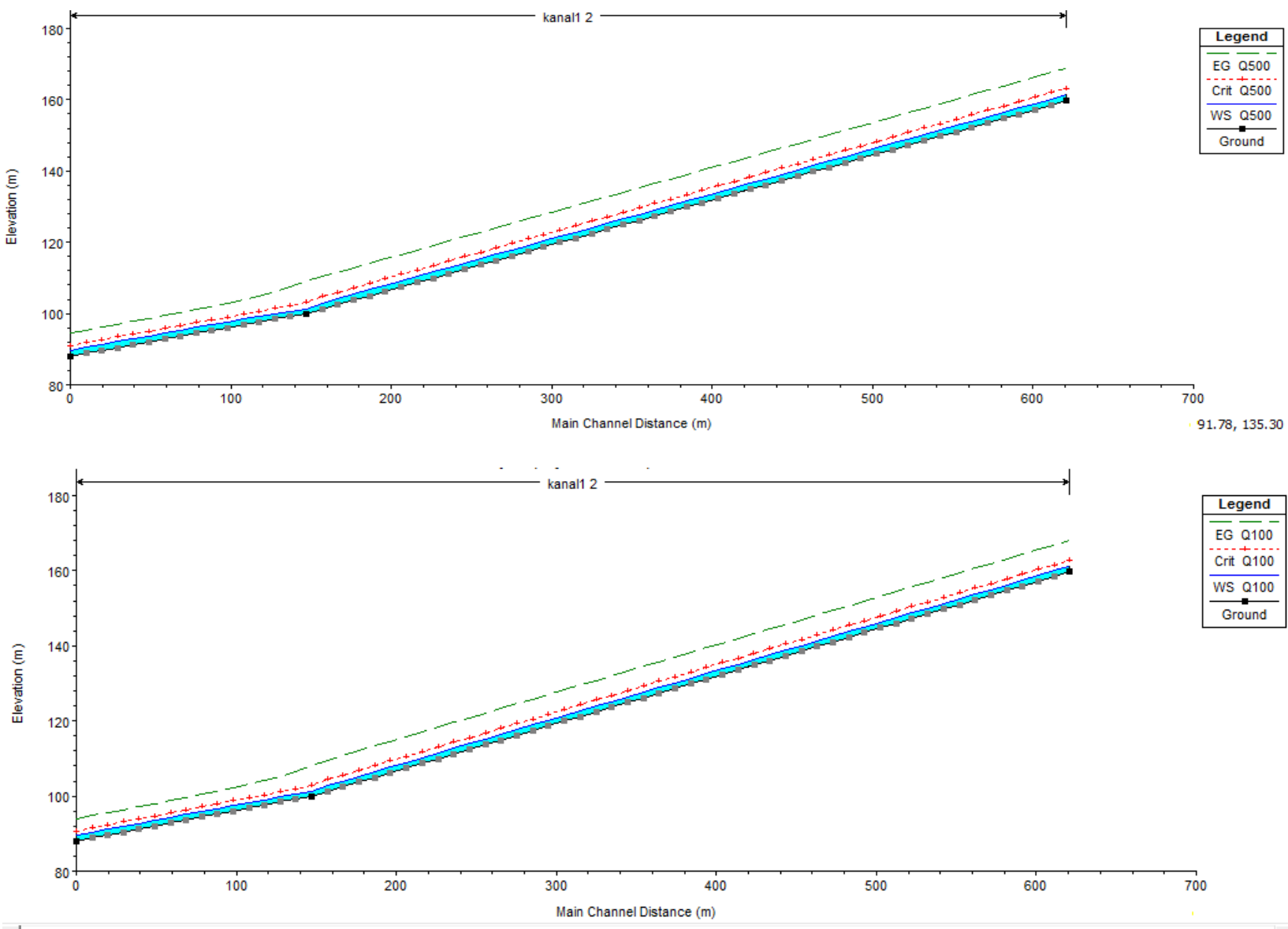

Şekil 2: Q500 ve Q100 modellerinin HEC-RAS profil kesiti görüntüsü

Daha sonra proje değerleri kullanılarak HEC-RAS programına veri girişleri yapılmıştır (Şekil 3). 


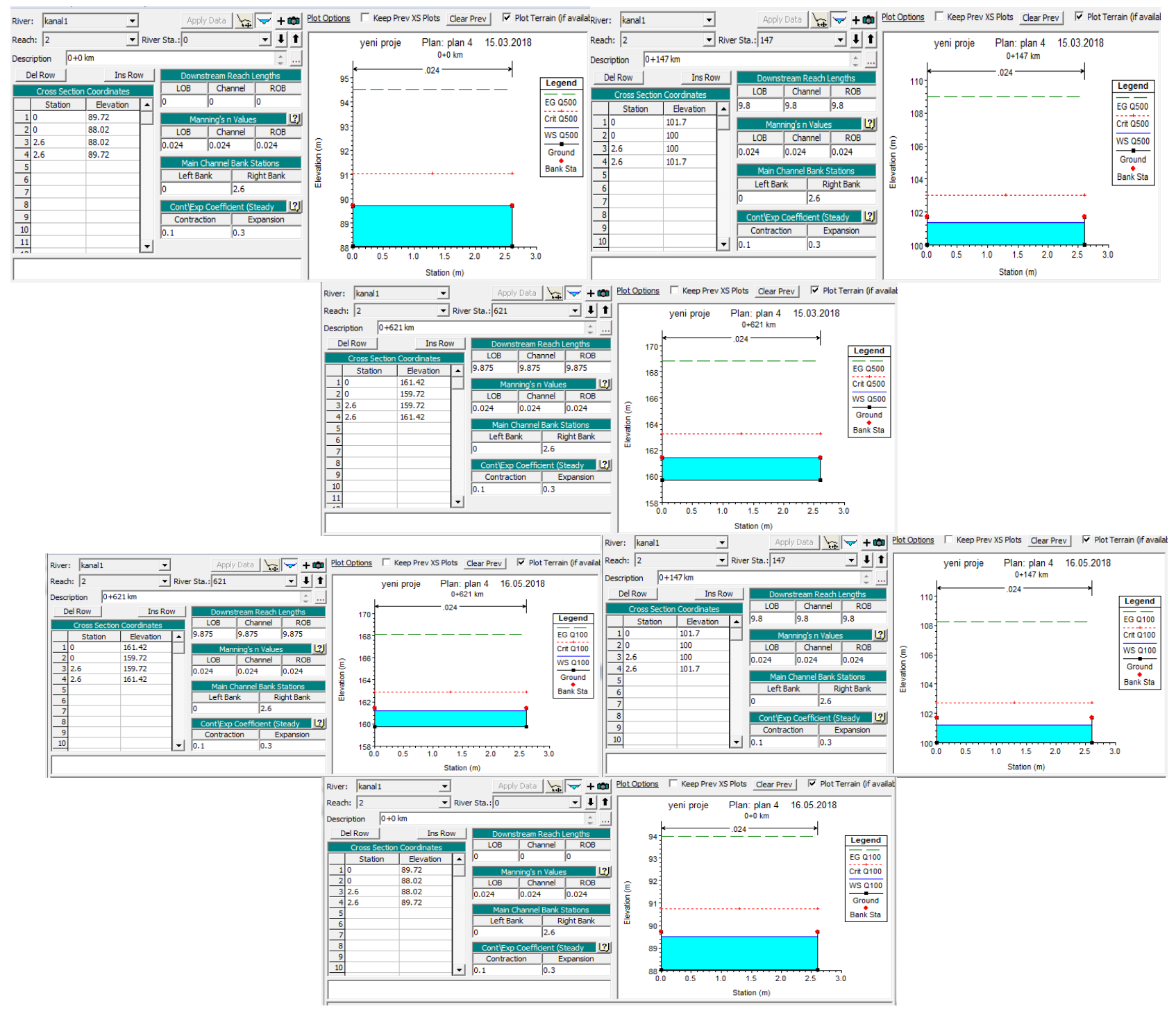

Şekil 3: Kesitlerin modellenmesi

\section{Bulgular ve Tartışma}

$\mathrm{Q}_{100}$ ve $\mathrm{Q}_{500}$ debi değerleri kullanılarak HEC-RAS programıyla modelleme yapılmıştır. Modelleme sonucunda su derinliği ve hız değerleri elde edilmiştir. Bu sonuçlar proje değerleri ile karşılaştııılmışıtır (Tablo 2, Şekil 4). Excel yardımıyla elde edilen proje değerleri ile HEC-RAS model sonuçları arasında oldukça yüksek bir uyum olduğu görülmektedir. HEC-RAS programı ile modelleme yapılan çalı̧̧ma alanının kritik altı, kritik üstü ve karışı rejimli akım türleri için istenilen noktalarından kesitler alınıp bu kesitler üzerinde o noktada ki hız, debi, Froude sayısı, minimum kanal eğimi, su yüzü yüksekliği, noktasal kanal eğimi ve alanı bilgilerine tablo halinde ulaşılabilmesi olanağı sağlamaktadır. HEC-RAS programı yardımıyla modelleme yapmak zaman kazancı ve hata riskini en aza indirmeyi sağlamaktadır. Ayrıca HECRAS modeli yardımıyla sonuçların görsel şekilleri ve grafikleri elde edilmiştir. Model üzerinde kolayca değişiklikler yapılmasına olanak sağlamaktadır.

Bir boyutlu su yüzü profili hesabı yapan bir yazılım olduğundan, ortalama kinetik enerji yüksekliği hesaplamasında her kesit için tek bir ortalama enerji değeri hesaplanır. Bu ortalama değer, ana kanal ile sağ ve sol taşkın kanalları enerji değerlerinin ortalaması alınarak hesaplanır. Bu yazılım yardımıyla yapılan modelleme sonunda noktalar arasındaki kritik hız farkları yada enerji kayıpları varsa bunlar rapor halinde uyarı olarak program tarafindan tespit edilmekte ve bu sonuçlar incelenip değerlendirilerek ilave en kesite ihtiyaç duyulan bölgeler tespit edilebilmektedir. Bu çalışmada kullanılan değerler ışığında elde edilen sonuçlar incelendiğinde kanal boyutlarının minimum şartları sağladığı sonucu çıkarılabilmektedir. Projenin excel sonuçları ve HEC-RAS verileri arasında karşılaştırmalar yapılmış ve bu sonuçlar 1şı̆̆ında HEC-RAS programının başarılı sonuçlar verdiği görülmüştür. 
Tablo 2: Q500 ve Q100 için proje ve model sonuçlarının karşılaştırılması

\begin{tabular}{|c|c|l|l|}
\hline \multicolumn{4}{|c|}{Q 500} \\
\hline \multicolumn{2}{|c|}{ Hız (m/s) } & \multicolumn{2}{c|}{ Su derinliği (m) } \\
\hline $\begin{array}{c}\text { HEC- } \\
\text { RAS } \\
\text { değerleri }\end{array}$ & $\begin{array}{c}\text { Proje } \\
\text { değerleri }\end{array}$ & $\begin{array}{c}\text { HEC- } \\
\text { RAS } \\
\text { değerleri }\end{array}$ & $\begin{array}{c}\text { Proje } \\
\text { değerleri }\end{array}$ \\
\hline 12.06 & 12.06 & 1.7 & 1.7 \\
12.06 & 12.06 & 1.7 & 1.7 \\
12.06 & 12.06 & 1.7 & 1.7 \\
12.06 & 12.06 & 1.7 & 1.7 \\
12.07 & 12.06 & 1.7 & 1.7 \\
12.07 & 12.06 & 1.7 & 1.7 \\
12.07 & 12.06 & 1.7 & 1.7 \\
12.07 & 12.06 & 1.7 & 1.7 \\
12.06 & 12.06 & 1.7 & 1.7 \\
12.06 & 12.06 & 1.7 & 1.7 \\
12.06 & 12.06 & 1.7 & 1.7 \\
9.78 & 9.70 & 1.69 & 1.7 \\
9.71 & 9.7025 & 1.7 & 1.7 \\
\hline
\end{tabular}

\begin{tabular}{|c|c|l|c|}
\hline \multicolumn{4}{|c|}{$Q_{100}$} \\
\hline \multicolumn{2}{|c|}{ Hız (m/s) } & \multicolumn{2}{c|}{ Su derinliği (m) } \\
\hline $\begin{array}{c}\text { HEC- } \\
\text { RAS } \\
\text { değerleri }\end{array}$ & $\begin{array}{c}\text { Proje } \\
\text { değerleri }\end{array}$ & $\begin{array}{c}\text { HEC- } \\
\text { RAS } \\
\text { değerleri }\end{array}$ & $\begin{array}{c}\text { Proje } \\
\text { değerleri }\end{array}$ \\
\hline 11.62 & 11.62 & 1.5 & 1.5 \\
11.62 & 11.62 & 1.5 & 1.5 \\
11.62 & 11.62 & 1.5 & 1.5 \\
11.62 & 11.62 & 1.5 & 1.5 \\
11.62 & 11.62 & 1.5 & 1.5 \\
11.62 & 11.62 & 1.5 & 1.5 \\
11.62 & 11.62 & 1.5 & 1.5 \\
11.62 & 11.62 & 1.5 & 1.5 \\
11.62 & 11.62 & 1.5 & 1.5 \\
11.62 & 11.62 & 1.51 & 1.5 \\
11.62 & 11.62 & 1.5 & 1.5 \\
9.04 & 9.34 & 1.49 & 1.5 \\
9.35 & 9.34 & 1.5 & 1.5 \\
\hline \multicolumn{4}{|c}{} \\
\hline
\end{tabular}

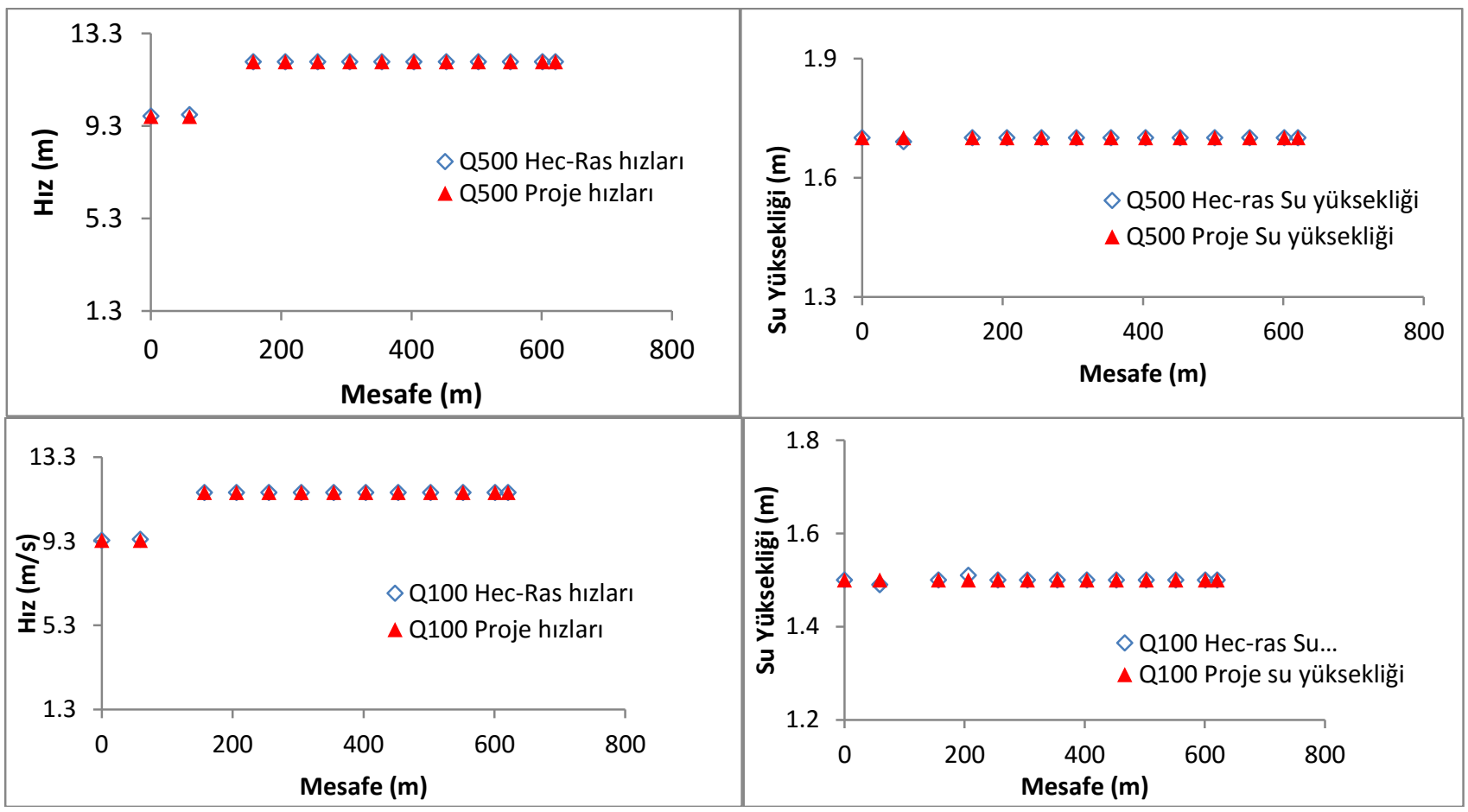

Şekil 4: Proje ve Model sonuçlarının karşılaştırılması

\section{Sonuçlar}

Su kaynakları yönetimi bir ülkenin sosyal ve ekonomik durumunun gelişiminde önemli bir role sahiptir. Canlıların yaşam kaynağı olan su kontrol altına alınmadığı durumlarda ciddi mal ve can kayıplarına neden olmaktadır. Su miktarının, doğal ve yapay olarak geçmesi istenen yatakların kapasitesini aşması sellere, su basmalarına ve taşkınlara sebep olur. Tüm dünyada olduğu gibi ülkemizde de büyük önem taşıyan taşkınların meydana getirdiği zararları azaltabilmek için bölge taşkın planları, hidrometrik ve meteorolojik gözlem çalışmaları, taşkın envanteri (taşkın yıllıkları); imar planları ile ilgili taşkın etütleri gibi taşkın zararlarını azaltma çalışmaları yapılmalıdır. Dere yatağı ıslah çalışmaları ve akarsu üzerindeki sanat yapılarının düzenlenmesi taşkın riskinde alınacak önlemlerden bazılarıdır. Bu tür çalışmaların yapılabilmesi için akarsu debisinin, su yüksekliği ve hızının bilinmesi gerekir. Projenin yapıldığı Kahramanmaraş ili Oniki Şubat ilçesinde bulunan 7 mahallede önceki yıllarda meydana gelen seller zararlara neden olmuştur ve yerleşim yeri olan bu bölgede bu 
zararların önüne geçebilmek amacıyla bu proje yapılmıştır. Bu çalışmada yağmur ve kar sularından kaynaklanan, taşkınların önüne geçmek amacıyla Mockus ve Rasyonel metot yöntemleri kullanılarak excel'de yapılmış olan Domuz deresi kuşaklama kanalının proje değerleri, HEC-RAS programı ile modellenip 2 yöntem arasındaki uyum ile programın sonuçları incelenmiştir. Domuz (Boğaz) Deresi Kuşaklama Kanalı'nın; 621 m uzunluğundaki parçasında meydana gelecek su derinlikleri ve hizları HEC-RAS (Hydrologic Engineering Center's - River Analysis System) programı kullanılarak modellenmiştir. İki farklı eğim ve iki farklı debi değerleri kullanılarak yapılan modelleme çalışması sonunda alınan 13 kesitte proje ve model sonuçlarının birbiriyle oldukça uyumlu olduğu görülmüştür.

\section{Kaynaklar}

Efe H., Önen F., (2015), Batman çayı'nın taşkın analizinin HEC-RAS programıyla yapılması, Dicle Üniversitesi Mühendislik Fakültesi - Mühendislik Dergisi, 6(2), 83-92.

Hicks F.E., Peacock T., (2005), Suitability of HEC-RAS for flood forecasting, Canadian Water Resources Journal / Revue canadienne des ressources hydriques, 30(2), 159-174.

Horritt M.S., Bates P.D., (2002), Evaluation of $1 D$ and 2D numerical models for predicting river flood inundation, Journal of Hydrology, 268, 87-99.

Mehta D.J., Ramani M., Joshi M., (2014), Application of 1-D HEC-RAS model in design of channels, International Journal of Innovative Research in Advanced Engineering (IJIRAE), 7(1), 103-107.

Özdemir H., (2007), Taşkınların haritalanmasında hec-georas ve HEC-RAS'ın kullanımı: havran çayı örneği (Balıkesir), TMMOB Harita ve Kadastro Mühendisleri Odası Ulusal Coğrafi Bilgi Sistemleri Kongresi, Trabzon, Türkiye, ss.1-9.

Ünsal M., Nalcığlu A., (2016), Kılavuzlu barajı sulama kanalında su derinliğinin HEC-RAS programı ile modellenmesi, Kahramanmaraş Sütçü İmam Üniversitesi Mühendislik Bilimleri Dergisi, 19(1), 41-45.

Üyüklüoğlu M., Ünal B., Turan B., (2015), HEC-RAS paket programı ile manavgat ilçesi ılıca deresi taşkın bölgesinin modellenmesi, 4. Su Yapıları Sempozyumu, Antalya, Türkiye, ss.428-438. 